\title{
Características Quantitativas, Composição Física Tecidual e Regional da Carcaça de Bezerros Machos de Origem Leiteira ao Nascimento, 50 e 110 Dias de Idade ${ }^{1}$
}

\author{
Paulo Afonso Carvalho², Luis Maria Bonnecarrère Sanchez ${ }^{3}$, João Pedro Velho ${ }^{4}$, Julio Viégas ${ }^{3}$, \\ Gilberto Cardoso Jauris ${ }^{5}$, Marcos Bittencourt Rodrigues ${ }^{6}$
}

\begin{abstract}
RESUMO - O presente estudo foi conduzido com o objetivo de avaliar o efeito da idade sobre características quantitativas de carcaça e composição tecidual de diferentes regiões da carcaça (dianteiro, costilhar, traseiro e secção 9a -11 $1^{\mathrm{a}}$ costelas) de bezerros na fase inicial da vida produtiva. Foram utilizados 18 bezerros machos de origem leiteira, dos quais seis foram abatidos ao nascimento, seis aos 50 dias e seis ao completarem 110 dias de idade. Os valores observados nas diferentes idades de abate (nascimento, 50 e110 dias de vida), demonstraram um comportamento linear crescente sobre as características quantitativas peso vivo ao abate (40,8; 59,7 e 87,0 kg), peso de carcaça quente (22,7; 30,9 e 41,9 kg), peso de carcaça fria (21,8; 30,1 e 40,7 kg), comprimento de carcaça (63,8; 75,0 e 82,8 cm), espessura de coxão (9,3; 10,0 e 12,2 cm), perímetro de braço (18,2; 22,1 e 23,3 cm) e área do músculo Longissimus dorsi (16,8; 20,2 e 22,4 cm²). O contrário ocorreu com as características rendimento de carcaça quente (55,4; 51,6 e 48,1\%) e rendimento de carcaça fria (53,2; 50,3 e 46,7 \%), que decresceram linearmente, em função do incremento da idade. Foi verificada uma redução no percentual de dianteiro (37,9; 35,4 e 35,0\%) e de tecido ósseo na carcaça (29,8; 28,6 e 25,5\%) assim como um acréscimo no percentual de traseiro (47,3; 50,6 e 51,0\%) e de tecido adiposo na carcaça (4,9; 5,4 e 7,3\%), conforme o desenvolvimento dos bezerros.
\end{abstract}

Palavras-chave: Características de carcaça, gordura, músculo, osso

\section{Characteristics and Composition of Dairy Male Calves Carcass at Newly Born, 50 and 110 Days of Age}

\begin{abstract}
The study was carried out at the Animal Production Department of the Universidade Federal of Santa Maria-RS, to evaluate the effect of age on carcass characteristics and composition of carcass regions (forequarter, rib, hindquarter and section 9a. 11 a ribs) at newly born calves. Eighteen animals distributed in three slaughter age (six at birth, six at 50 days and six at 110 days of age), were used. The quantitative characteristics of slaughter live weight (40.8; 59.7 and $87.0 \mathrm{~kg})$, hot (22.7; 30.9 and $41.9 \mathrm{~kg}$ ) and cold carcass weight (21.8; 30.1 and $40.7 \mathrm{~kg}$ ), carcass length (63.8; 75.0 and $82.8 \mathrm{~cm})$, round thickness (9.3; 10.0 and $12.2 \mathrm{~cm})$, hand perimeter (18.2; 22.1 and $23.3 \mathrm{~cm})$ and Longissimus dorsi muscle area $\left(16.8 ; 20.2\right.$ and $\left.22.4 \mathrm{~cm}^{2}\right)$ were increased linearly, according to the age increase. Hot (55.4; 51.6 and 48.1\%) and cold (53.2; 50.3 and 46.7\%) carcass dressing percentage decreased linearly with age increase. As the animals grew the proportions of forequarter (37.9; 35.4 and 35.0\%) and bone tissue in carcass (29.8; 28.6 and $25.5 \%$ ) were reduced and those of hidquarter (47.3; 50.6 and 51.0\%) and fat carcass tissue (4.9; 5.4 and 7.3\%) were increased.
\end{abstract}

Key Words: bone, carcass characteristics, fat, muscle

\section{Introdução}

No atual sistema de criação de bovinos leiteiros, o animal nascido macho recebe um tratamento bastante inferior em relação à fêmea e isto é justificado pelo fato de o objetivo principal do sistema ser a produção leiteira e, portanto, a fêmea acaba recebendo um tratamento especial. No entanto, existe probabilidade de $50 \%$ de os animais nascerem ma- chos, representando elevado número de bezerros subaproveitados, eliminando-se importante fonte de renda (Signoretti et al., 1995).

Nos países de pecuária leiteira desenvolvida, o aproveitamento dos bezerros oriundos de rebanhos leiteiros, para a produção de carne, é uma realidade, representando uma parcela significativa da carne consumida pela população. Existem vários sistemas de produção com esse objetivo. Na Holanda, França

\footnotetext{
${ }^{1}$ Parte da Dissertação apresentada à Universidade Federal de Santa Maria (UFSM), pelo primeiro autor como um dos requisitos para obtenção do Título de Mestre em Zootecnia.

2 Zootecnista, M.Sc. Doutorando pela Universidade Federal de Lavras (UFLA). Bolsista CNPq. Rua Progresso, 41/801. Lavras, MG. 37200-000. Autor para correspondência. E.mail: pac@ufla.br

3 Professor do Departamento de Zootecnia da UFSM, RS.

${ }^{4}$ Acadêmico de Zootecnia (UFSM) - Bolsista de iniciação científica CNPq.

${ }^{5}$ Professor da Escola Agrotécnica Federal de São Vicente do Sul, RS.

${ }^{6}$ Médico Veterinário - Colaborador do Setor de Nutrição de Ruminantes da UFSM.
} 
e Itália, principalmente, e em menor escala nos Estados Unidos e Canadá, bezerros predominantemente de raças leiteiras, são abatidos às 16-18 semanas de idade (112-126 dias) com 160-170 kg de peso vivo para produção de vitelos (Campos et al., 1997).

No Brasil, existem poucos estudos sobre a qualidade das carcaças destes animais abatidos precocemente, para serem consumidos na forma de vitelos ou criados até a puberdade, quando a carne apresenta características semelhantes à de animais adultos, mas com melhor qualidade, principalmente no tocante à maciez.

De acordo com Velloso et al. (1975), animais originários de rebanhos leiteiros apresentam boa habilidade de ganho de peso e um bom desempenho em confinamento. Da mesma forma, Banys (1999) afirma que o gado Holandês não deve ser considerado uma raça exclusivamente leiteira, apesar de ser esta a sua função principal. O desenvolvimento do esqueleto com massas musculares e, sobretudo, o potencial para ganho de peso e conversão alimentar são favoráveis a essa raça em relação à produção de carne, proporcionando pequena cobertura de tecido adiposo.

No entanto, no contexto da realidade brasileira, o aproveitamento racional para corte, dos bezerros originários de propriedades produtoras de leite requer melhor avaliação do potencial de crescimento e das características de carcaça, tendo em vista que a restrição alimentar normalmente imposta a estes animais na fase de cria pode refletir sobre o desempenho posterior, como animais de abate (Rocha et al., 1999).

Segundo Teixeira (1984), o conhecimento da composição da carcaça de bovinos tanto em terminação como em crescimento é relevante, pois permite identificar os animais com habilidade de produzir eficientemente melhores carcaças beneficiando os setores de produção e comercialização. Além de contribuir valiosamente com os estudos de requisitos nutricionais.

A composição física da carcaça compreende a quantidade de osso, músculo e gordura, sendo que a proporção destes constituintes muda à medida que 0 animal se desenvolve, apresentando diferentes tendências de crescimento tecidual. Estas proporções podem ser modificadas pela idade, sexo, fatores genéticos e ambientais e influem diretamente na composição das carcaças produzidas e indiretamente sobre as exigências nutricionais dos animais (Fox \& Black, 1984).

Ao nascimento existem na carcaça cerca de duas partes de músculo para uma de osso, no entanto, o músculo cresce relativamente mais rápido no período pós-natal do que o osso, fazendo com que a relação de músculo para osso aumente. Já a gordura, que representa uma porção pequena ao nascimento, aumenta de maneira mais acentuada após a maturidade fisiológica, sendo o tecido mais variável do organismo animal e de mais fácil manipulação na carcaça (Berg \& Butterfield, 1976).

De acordo com Keplin (1989), normalmente o peso vivo de abate é utilizado como medida de produção total do animal. No entanto, o peso de carcaça é uma medida mais real para avaliar a porção comestível durante o período de crescimento ou terminação. A importância do conhecimento sobre as características das carcaças é fundamental na busca da melhoria da qualidade potencial do produto final.

O presente estudo foi conduzido com o objetivo de avaliar as características quantitativas de carcaça, o desenvolvimento e composição física tecidual regional e total da carcaça, no início da vida produtiva de bezerros de origem leiteira.

\section{Material e Métodos}

Foram abatidos 18 bezerros machos, não castrados, da raça Holandês, sendo seis ao nascimento, seis aos 50 dias e seis ao completarem 110 dias de idade. Antecedendo o momento do abate os animais foram pesados em balança mecânica e, logo após, pendurados pelos membros traseiros e sacrificados por secção da veia jugular. Foi realizada a esfola para a retirada do couro e procedida a abertura do osso esterno do peito bem como da cavidade abdominal, para a retirada dos órgãos e vísceras.

Foram separadas do corpo e pesadas as patas e a cabeça e efetuado um corte longitudinal dividindo a carcaça ao meio. Depois de verificado o peso da carcaça quente, a mesma foi resfriada em câmara frigorífica à temperatura de $2^{\circ} \mathrm{C}$ por 24 horas.

Foram observadas, de acordo com Lauzer (1977) e Perobelli (1993), as seguintes variáveis relativas às características quantitativas de carcaça:

- Peso de carcaça quente (PCQ): peso (kg) obtido logo após o abate.

- Peso de carcaça fria (PCF): peso (kg) obtido após 24 h em câmara fria.

- Quebra ao resfriamento (QR): diferença $(\mathrm{kg})$ entre o peso de carcaça quente e o peso de carcaça fria.

\section{R. Bras. Zootec., v.32, n.6, p.1476-1483, 2003}


- Rendimento de carcaça quente (RCQ): relação percentual entre o peso vivo ao abate e o peso de carcaça quente.

- Rendimento de carcaça fria (RCF): relação percentual entre o peso vivo ao abate e o peso de carcaça fria.

· Índice de quebra ao resfriamento (IQ): relação percentual entre o peso de carcaça quente e o peso de carcaça fria.

- Comprimento de carcaça (CC): medido (cm) com fita métrica metálica, desde o bordo anterior do osso púbis até o bordo cranial da primeira costela.

- Espessura de coxão (EC): medido (cm) com o auxílio de um compasso de pontas metálicas, colocadas na face lateral e medial da porção superior do coxão. Após, foi medida a abertura do compasso.

- Perímetro de braço (PB): medido (cm) com uma fita métrica de nylon no ponto médio do comprimento do braço.

- Área do músculo Longissimus dorsi (AMLD): obtida por exposição do músculo após corte transversal na carcaça, entre a $12^{\mathrm{a}}$ e $13^{\mathrm{a}}$ costelas, através do traçado do contorno do músculo em papel vegetal, conforme Müller (1987). Para determinação da área $\left(\mathrm{cm}^{2}\right)$ foi utilizado o programa Sister 2.2, com mesa digitalizadora modelo A.2 pertencente ao Departamento de Engenharia Rural da UFSM, conforme procedimento de Carvalho (1998).

Após o resfriamento, realizou-se o seccionamento da carcaça em diferentes regiões de constituição:

- Dianteiro (DIANT): por corte transversal entre a 8a-9a vértebra torácica.

- Costilhar (COST): por corte longitudinal rente ao músculo Longissimus dorsi.

- Traseiro (TRAS): por corte transversal entre a $11^{\mathrm{a}}-12^{\mathrm{a}}$ vértebra torácica, ficando com as duas últimas costelas.

- Secção 9a -11 a costelas (SECÇÃO 9-11): porção compreendida entre a $9^{\mathrm{a}}-11^{\mathrm{a}}$ costelas com vértebra, cortada longitudinalmente à altura de $61 \%$ do comprimento da costela, a partir da vértebra torácica correspondente, conforme metodologia descrita por Hankins \& Howe (1946).

A composição tecidual foi determinada de maneira direta, pela separação física total dos tecidos de constituição nas diferentes regiões da carcaça, sendo analisado o percentual de osso, músculo e gordura no dianteiro (DIANT), costilhar (COST), traseiro (TRAS), assim como na secção $9^{\mathrm{a}}-11^{\mathrm{a}}$ costelas (SECÇÃO 9-11). Os dados obtidos na SECÇÃO
9 -11 foram considerados na composição do COST. O somatório da composição tecidual nas diferentes regiões permitiu a obtenção dos dados de carcaça (CARC). Todas as medições foram realizadas na $1 \frac{1}{2}$ carcaça esquerda e depois extrapolado para a carcaça inteira. Também foi feita a separação física nas patas (PAT) e cabeça (CAB).

O delineamento experimental foi inteiramente casualisado, constando de três tratamentos (idades de abate) e seis repetições por tratamento, sendo a unidade experimental representada por um animal.

Os dados foram analisados através do programa SAS (1996), onde foram submetidos à análise de regressão sendo considerada como variável dependente a característica analisada e como variável independente a idade do animal.

\section{Resultados e Discussão}

Os valores obtidos para as características de produção quantitativa das carcaças são apresentados na Tabela 1.

Foi verificado comportamento linear positivo para as características peso vivo ao abate (PVA), peso de carcaça quente (PCQ), peso de carcaça fria (PCF), quebra ao resfriamento (QR), comprimento de carcaça (CC), espessura de coxão (EC), perímetro de braço (PB), área do músculo Longissimus dorsi (AMLD) e porcentagem de traseiro (TRAS). O contrário ocorreu com as características rendimento de carcaça quente (RCQ), rendimento de carcaça fria (RCF), índice de quebra (IQ) e porcentagem de dianteiro (DIANT), que decresceram linearmente em função do incremento da idade, até 110 dias de vida, conforme demonstrado na Tabela 1.

As regressões lineares ajustadas foram significativas ao nível de $1 \%$ para todas as características avaliadas, exceto QR, a qual foi significativa a $5 \%$ e para porcentagem de costilhar (COST) na carcaça, que não ajustou regressão significativa $(\mathrm{P}>0,05)$, em função do incremento de idade.

Campos et al. (1997) relatam para bezerros da raça Holandês aos 30 dias de idade um PVA de $57 \mathrm{~kg}$, um PCQ de $31 \mathrm{~kg}$ e um RCQ de 54\%. Estes dados concordam com os resultados do presente estudo que obteve, por estimativa aos 30 dias de vida valores de $53 \mathrm{~kg}$ de PVA, $28 \mathrm{~kg}$ de PCQ e 53\% de RCQ.

Signoretti et al. (1999) submeteram 20 bezerros da raça Holandês, com $78 \mathrm{~kg}$ de peso vivo médio inicial a uma dieta constituída por níveis crescentes 
Tabela 1 - Valores médios, coeficientes de determinação $\left(r^{2}\right)$ e equações de regressão ajustadas para as características quantitativas de carcaça em função da idade (IDA) em dias

Table 1 - Means values, determination coefficients $\left(\mathrm{r}^{2}\right)$ and fitted regression equations for quantitative characteristics of the carcass, according to the days age (IDA)

\begin{tabular}{|c|c|c|c|c|c|}
\hline \multirow[t]{2}{*}{$\begin{array}{l}\text { Característica } \\
\text { Characteristic }\end{array}$} & \multicolumn{3}{|c|}{$\begin{array}{l}\text { Idade (dias) } \\
\text { Age (days) }\end{array}$} & \multirow[b]{2}{*}{$r^{2}(\%)$} & \multirow[b]{2}{*}{$\begin{array}{c}\text { Equações de regressão } \\
\text { Regression equations }\end{array}$} \\
\hline & $\begin{array}{l}\text { Nascimento } \\
\text { Birth }\end{array}$ & 50 & 110 & & \\
\hline $\begin{array}{l}\text { PVA }(\mathrm{kg})^{1} \\
S L W\end{array}$ & 40,835 & 59,792 & 87,025 & 87,32 & $\ddot{Y}=40,095659+0,421029 * *$ IDA \\
\hline $\begin{array}{l}\text { PCQ }(\mathrm{kg})^{2} \\
H C W\end{array}$ & 22,675 & 30,892 & 41,875 & 78,07 & $\ddot{Y}=22,489835+0,174826 * *$ IDA \\
\hline $\begin{array}{l}\operatorname{PCF}(\mathrm{kg})^{3} \\
C C W\end{array}$ & 21,786 & 30,072 & 40,690 & 78,88 & $\ddot{Y}=21,674705+0,172021 * *$ IDA \\
\hline $\begin{array}{l}\mathrm{QR}(\mathrm{kg})^{4} \\
C B\end{array}$ & 0,889 & 0,819 & 1,186 & 24,87 & $\ddot{Y}=0,815130+0,002805 *$ IDA \\
\hline $\begin{array}{l}\mathrm{RCQ}(\%)^{5} \\
H C D\end{array}$ & 55,36 & 51,64 & 48,08 & 70,72 & $\ddot{Y}=55,209615-0,065962 * *$ IDA \\
\hline $\begin{array}{l}\mathrm{RCF}(\%)^{6} \\
C C D\end{array}$ & 53,18 & 50,27 & 46,72 & 69,87 & $\ddot{Y}=53,192784-0,058802 * *$ IDA \\
\hline $\begin{array}{l}\mathrm{IQ}(\%)^{7} \\
B Y\end{array}$ & 3,93 & 2,65 & 2,82 & 41,49 & $\ddot{Y}=3,645458-0,009665^{* *}$ IDA \\
\hline $\begin{array}{l}\mathrm{CC}(\mathrm{cm})^{8} \\
C L\end{array}$ & 63,83 & 75,00 & 82,83 & 78,18 & $\ddot{Y}=64,750916+0,171337 * *$ IDA \\
\hline $\begin{array}{l}\mathrm{EC}(\mathrm{cm})^{9} \\
T R\end{array}$ & 9,30 & 10,00 & 12,17 & 68,71 & $\ddot{Y}=9,081319+0,026392 * *$ IDA \\
\hline $\begin{array}{l}\mathrm{PB}(\mathrm{cm})^{10} \\
H P\end{array}$ & 18,20 & 22,08 & 23,33 & 56,08 & $\ddot{\mathrm{Y}}=18,762088+0,045815^{* *} \mathrm{IDA}$ \\
\hline $\begin{array}{l}\operatorname{AMLD}\left(\mathrm{cm}^{2}\right)^{11} \\
\text { LDMA }\end{array}$ & 16,81 & 20,15 & 22,43 & 42,28 & $\ddot{\mathrm{Y}}=17,096319+0,050642 * *$ IDA \\
\hline $\begin{array}{l}\text { DIANT }(\%)^{12} \\
\text { FOREQ }\end{array}$ & 37,92 & 35,36 & 34,97 & 50,15 & $\ddot{Y}=37,484011-0,026211^{* *}$ IDA \\
\hline $\begin{array}{l}\operatorname{COST}(\%)^{13} \\
\operatorname{RIB}\end{array}$ & 14,81 & 14,08 & 14,03 & - & $\ddot{Y}=14,31$ \\
\hline $\begin{array}{l}\text { TRAS }(\%)^{14} \\
\text { HINDQ }\end{array}$ & 47,27 & 50,56 & 51,00 & 62,79 & $\ddot{Y}=47,644139+0,033110 * *$ IDA \\
\hline
\end{tabular}

** $(\mathrm{P}<0,01), \quad *(\mathrm{P}<0,05)$.

${ }^{1} \mathrm{PVA}=$ peso vivo ao abate, ${ }^{2} \mathrm{PCQ}=$ peso de carcaça quente, ${ }^{3} \mathrm{PCF}=$ peso de carcaça fria, ${ }^{4} \mathrm{QR}=$ quebra ao resfriamento,

${ }^{5} \mathrm{RCQ}=$ rendimento de carcaça quente, ${ }^{6} \mathrm{RCF}=$ rendimento de carcaça fria, ${ }^{7} \mathrm{IQ}=$ índice de quebra, ${ }^{8} \mathrm{CC}=$ comprimento de carcaça,

${ }^{9} \mathrm{EC}=$ espessura de coxão, ${ }^{10} \mathrm{~PB}=$ perímetro de braço, ${ }^{11} \mathrm{AMLD}=$ área do músculo Longissimus dorsi, ${ }^{12}$ DIANT = dianteiro,

${ }^{13} \mathrm{COST}=$ costilhar, ${ }^{14 \mathrm{~T}} \mathrm{RAS}=$ traseiro.

${ }^{1} \mathrm{SLW}=$ slaughter live weight, ${ }^{2} \mathrm{HCW}=$ hot carcass weight, ${ }^{3} \mathrm{CCW}=$ cold carcass weight, ${ }^{4} \mathrm{CB}=$ cold to break, ${ }^{5} \mathrm{HCD}=$ hot carcass dressing, ${ }^{6} \mathrm{CCD}=$ cold carcass dressing, ${ }^{7} \mathrm{BY}=$ break yield, ${ }^{8} \mathrm{CL}=$ carcass length, ${ }^{9} \mathrm{TR}=$ thickness round, ${ }^{10} \mathrm{HP}=$ hand perimeter, ${ }^{11} \mathrm{LDMA}=\mathrm{Longissimus} \mathrm{dorsi} \mathrm{muscle} \mathrm{area,}$

${ }^{12} \mathrm{FOREQ}=$ forequarter, ${ }^{13} \mathrm{RIB}=$ rib, ${ }^{14} \mathrm{HINDQ}=$ hindquarter.

de volumoso, até atingirem $190 \mathrm{~kg}$ ou $300 \mathrm{~kg}$ de PV, quando foram abatidos. Foi verificada uma redução linear decrescente $(\mathrm{P}<0,01)$ para o RCQ até os animais atingirem $190 \mathrm{~kg}$, a partir do que o RCQ não foi influenciado pelo nível de volumoso. Os autores justificam que a redução no RCQ com o incremento de volumoso na dieta ocorre devido ao enchimento do trato gastrintestinal até um certo limite de PV, a partir do qual, maiores ganhos são obtidos em função de reservas corporais e não de conteúdo alimentar. Tais constatações são concordantes com Euclides Filho et al. (1997), Müller et al. (1997), Araújo et al. (1998),
Silva et al. (1999), bem como concordam com os resultados obtidos no presente trabalho, que apresentou comportamento linear decrescente $(\mathrm{P}<0,01)$ para RCQ com o incremento de idade e enchimento do trato digestivo, cujo CGI aumentou de 6,7 para 21,8 kg do nascimento até os 110 dias de vida.

Os maiores IQ observados para os animais mais jovens pode ser justificado devido à ausência de gordura de cobertura e maior proporção de água nos tecidos dos bezerros, concordando com Berg \& Butterfield (1976), os quais verificaram semelhante composição corporal em animais jovens. Tal 
constatação vem de encontro aos resultados obtidos por Del Duca et al. (1999), que observaram uma redução no índice de quebra ao resfriamento, à medida que os animais aumentaram o peso vivo e a espessura de gordura da carcaça.

Foi verificada uma elevada proporção de dianteiro nos bezerros ao nascimento, decrescendo $(\mathrm{P}<0,01)$ com o avanço da idade até os 110 dias de vida, quando representou 34,97 \% da carcaça. Já o percentual de traseiro apresentou um comportamento de desenvolvimento crescente $(\mathrm{P}<0,01)$ até os 110 dias de vida, quando representou 51,00 \% da carcaça. Rocha et al. (1999) encontraram valores proporcionais de dianteiro na ordem de $38,23 \%$ e traseiro de $61,77 \%$ para novilhos da raça Holandês abatidos com 200 kg PV. Uma maior proporção de traseiro é desejável, uma vez que nesta parte da carcaça é que se encontram os cortes mais nobres e valorizados.

Foi verificada (Tabela 2) diminuição $(\mathrm{P}<0,05)$ na porcentagem de osso e aumento $(\mathrm{P}<0,01)$ na porcentagem de godura na carcaça, à medida que os animais se desenvolveram. No entanto, esse comportamento não foi observado para todas as regiões corporais analisadas, indicando que as distintas partes que compõem a carcaça apresentam taxas de crescimento diferenciadas.

As porcentagens de osso no dianteiro $(\mathrm{P}<0,05)$ e na cabeça $(\mathrm{P}<0,01)$, reduziram linearmente com 0 incremento da idade. Todavia, as porcentagens de osso no costilhar, traseiro, secção $9^{\mathrm{a}}-11^{\mathrm{a}}$ costelas e patas, assim como as porcentagens de músculo no dianteiro, costilhar, traseiro, secção $9^{\mathrm{a}}-11^{\mathrm{a}}$ costelas e patas não apresentaram regressões significativas ( $\mathrm{P}>0,05)$, em função do aumento da idade, até os 110 dias de vida.

As porcentagens de gordura no dianteiro $(\mathrm{P}<0,01)$, traseiro $(\mathrm{P}<0,05)$ e secção $9^{\mathrm{a}}-11^{\mathrm{a}}$ costelas $(\mathrm{P}<0,05)$ apresentaram comportamento crescente, conforme o incremento da idade. A proporção de gordura no costilhar não apresentou regressão significativa $(\mathrm{P}>0,05)$, de acordo com o aumento da idade dos bezerros.

O comportamento de desenvolvimento tecidual do presente estudo concorda com achados de Peron et al. (1995) os quais avaliaram diferentes categorias de bovinos e encontraram que as proporções de ossos na carcaça reduziram $(\mathrm{P}<0,05)$, enquanto as proporções de gordura aumentaram com o desenvolvimento dos animais. Da mesma maneira, Keplin (1989) trabalhando com novilhos da raça Charolês, encontrou valores decrescentes para a porcentagem de osso na carcaça e crescente para a porcentagem de gordura, conforme o incremento de PV dos animais avaliados. Essas modificações na composição tecidual da carcaça são explicadas por Fox \& Black (1984), os quais afirmam que diferentes composições teciduais da carcaça estão intimamente relacionadas a diferentes taxas de crescimento e composições do ganho de peso, determinando exigências nutricionais distintas para as categorias animais.

Na Tabela 3, estão tabulados os dados referentes às relações existentes entre os tecidos de constituição (músculo, osso e gordura) nas diferentes regiões corporais, bem como a relação entre a área do músculo Longissimus dorsi e os tecidos muscular e adiposo da carcaça.

Foi verificado comportamento linear decrescente ( $\mathrm{P}<0,01)$, em função da idade, para a relação músculo/ gordura no dianteiro e na carcaça. Tal comportamento indica aumento do acúmulo de gordura em relação ao tecido magro nesses dois locais, em função do aumento da idade dos animais. No entanto, o acúmulo de gordura na carcaça é função do somatório da gordura acumulada nas diferentes regiões, de onde se deduz que a relação músculo/gordura da carcaça pode estar sendo influenciada, nessa fase, pelo acúmulo precoce de gordura no dianteiro. A proporção de músculo, nas diferentes regiões corporais, não sofreu grandes alterações até os 110 dias de idade.

Em um estudo conduzido por Robelin \& Geay (1984), citados por Di Marco (1994), a relação músculo/gordura estimada da carcaça diminuiu de 10,04 para 8,37, quando o peso corporal vazio (PCVZ) de bezerros aumentou de 50 para $100 \mathrm{~kg}$. Tal constatação indica aumento na proporção de gordura em relação à proporção de músculos na carcaça com o incremento de PCVZ, concordando com o presente estudo.

A relação existente entre a área do músculo Longissimus dorsi e as proporções de músculo e gordura na carcaça diminuíram linearmente $(\mathrm{P}<0,01)$ com o aumento de idade dos bezerros, indicando existir desenvolvimento pós-natal muscular e gorduroso da carcaça. Esse comportamento é verificado de maneira mais intensa com relação ao tecido adiposo do que com o muscular, conforme demonstra os coeficientes de regressão obtidos pelas equações ajustadas. 
Tabela 2 - Valores médios proporcionais, coeficientes de determinação $\left(r^{2}\right)$ e equações de regressão ajustadas para composição tecidual do dianteiro, costilhar, traseiro, secção 9a-11a costelas (Secção 9-11), patas, cabeça e carcaça, em função da idade (IDA), em dias

Table 2 - Proportional means values, determination coefficients $\left(r^{2}\right)$ and fitted regression equations for tissue composition to hindquarter, rib, forequarter, $9^{\text {th }}-11^{\text {th }}$ rib section (section 9-11), leg, head and carcass, according to the days age (IDA)

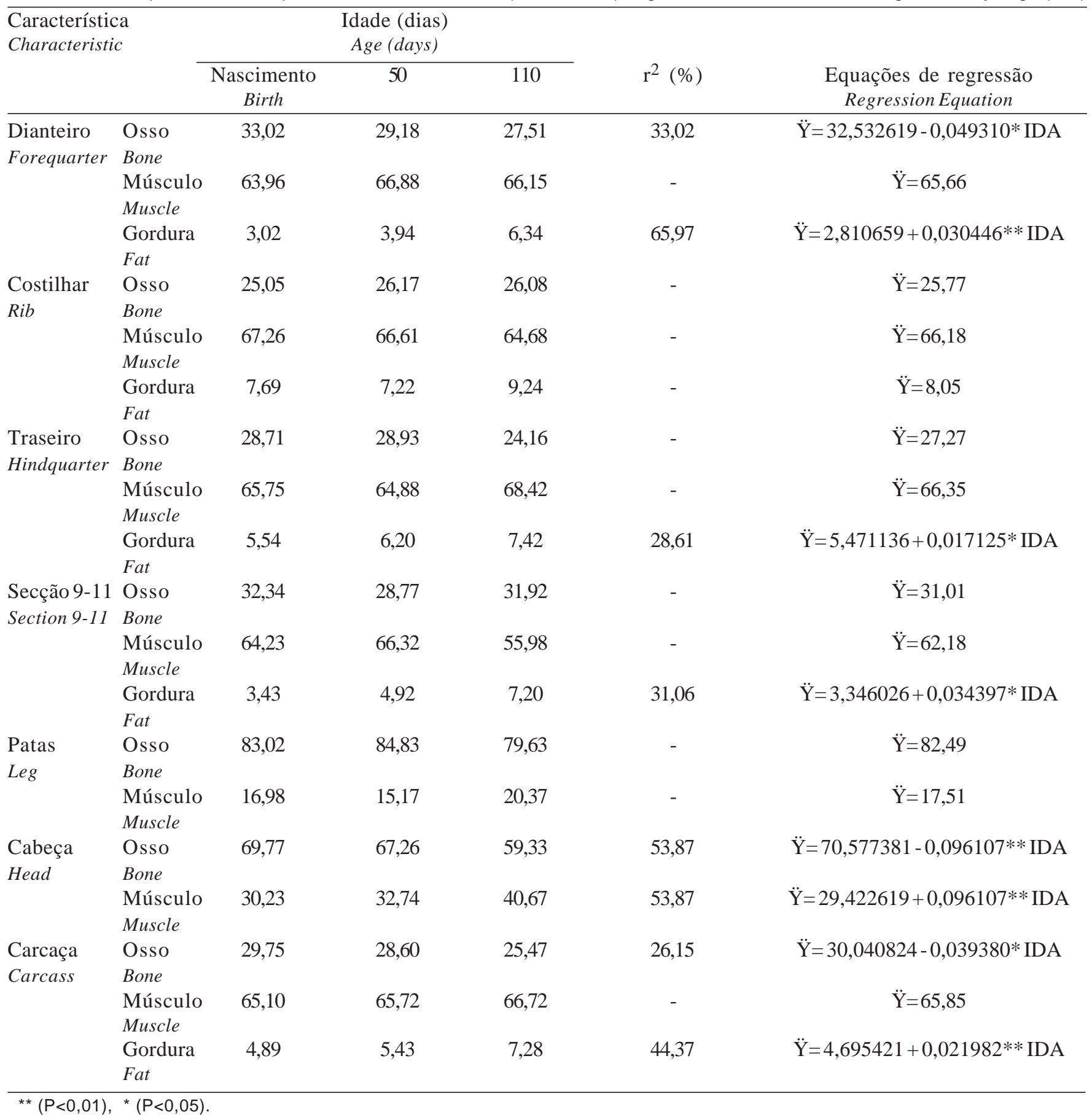


Tabela 3 - Valores médios, coeficientes de determinação $\left(r^{2}\right)$ e equações de regressão ajustadas para relação músculo/ osso e músculo/gordura do dianteiro, costilhar, traseiro, secção 9â-11a costelas (Secção 9-11) e da carcaça e relação área do músculo Longissimus dorsi/músculo da carcaça (AMLD/CARM) e área do músculo Longissimus dorsilgordura da carcaça (AMLD/CARG), em função da idade (IDA) em dias

Table 3 - Means values, determination coefficients $\left(r^{2}\right)$ and fitted regression equations for muscle/bone and muscle/fat relation to hindquarter, rib, forequarter, 9a-11a rib section (section 9-11) and carcass and Longissimus dorsi muscle area/carcass muscle (LDMA/CARM) and Longissimus dorsi muscle area/carcass fat (LDMA/CARF) in according to the days age (IDA)

Característica

Characteristic Age (days) Idade (dias)

\begin{tabular}{|c|c|c|c|c|c|c|}
\hline & & $\begin{array}{l}\text { Nascimento } \\
\text { Birth }\end{array}$ & 50 & 110 & $r^{2}(\%)$ & $\begin{array}{l}\text { Equações de regressão } \\
\text { Regression Equation }\end{array}$ \\
\hline \multirow{3}{*}{$\begin{array}{l}\text { Dianteiro } \\
\text { Forequarter }\end{array}$} & Musc/Osso ${ }^{1}$ & 1,95 & 2,39 & 2,45 & - & $\ddot{\mathrm{Y}}=2,26$ \\
\hline & Muscle/Bone & & & & & \\
\hline & $\begin{array}{l}\text { Musc/Gord } 2 \\
\text { Muscle/Fat }\end{array}$ & 21,31 & 18,82 & 10,75 & 52,42 & $\ddot{\mathrm{Y}}=22,143205-0,097237 * *$ IDA \\
\hline \multirow{3}{*}{$\begin{array}{l}\text { Costilhar } \\
\text { Rib }\end{array}$} & Musc/Osso & 2,71 & 2,62 & 2,50 & - & $\ddot{Y}=2,61$ \\
\hline & Muscle/Bone & & & & & \\
\hline & $\begin{array}{l}\text { Musc/Gord } \\
\text { Muscle/Fat }\end{array}$ & 8,86 & 10,24 & 7,73 & - & $\ddot{Y}=8,94$ \\
\hline \multirow{3}{*}{$\begin{array}{l}\text { Traseiro } \\
\text { Hindquarter }\end{array}$} & Musc/Osso & 2,70 & 2,26 & 2,86 & - & $\ddot{Y}=2,61$ \\
\hline & Muscle/Bone & & & & & \\
\hline & $\begin{array}{l}\text { Musc/Gord } \\
\text { Muscle/Fat }\end{array}$ & 11,93 & 11,19 & 9,47 & - & $\ddot{Y}=10,86$ \\
\hline \multirow{3}{*}{$\begin{array}{l}\text { Secção 9-11 } \\
\text { Section 9-11 }\end{array}$} & Musc/Osso & 2,00 & 2,36 & 2,17 & - & $\ddot{Y}=2,18$ \\
\hline & Muscle/Bone & & & & & \\
\hline & $\begin{array}{l}\text { Musc/Gord } \\
\text { Muscle/Fat }\end{array}$ & 19,77 & 18,52 & 10,93 & - & $\ddot{Y}=16,41$ \\
\hline \multirow{3}{*}{$\begin{array}{l}\text { Carcaça } \\
\text { Carcass }\end{array}$} & Musc/Osso & 2,28 & 2,32 & 2,64 & - & $\ddot{Y}=2,41$ \\
\hline & Muscle/Bone & & & & & \\
\hline & $\begin{array}{l}\text { Musc/Gord } \\
\text { Muscle/Fat }\end{array}$ & 13,36 & 12,68 & 9,40 & 36,00 & $\ddot{Y}=13,767491-0,036630 * *$ IDA \\
\hline $\begin{array}{l}\text { AMLD/CARM } \\
\text { LDMA/CARM }\end{array}$ & & 1,19 & 1,03 & 0,83 & 60,09 & $\ddot{Y}=1,193718-0,003288 * * I D A$ \\
\hline $\begin{array}{l}\text { AMLD/CARG } \\
L D M A / C A R F\end{array}$ & & 16,05 & 13,24 & 7,70 & 55,55 & $\ddot{Y}=16,404212-0,076433 * *$ IDA \\
\hline
\end{tabular}

\section{Conclusões}

Verifica-se incremento nas características quantitativas de carcaça, à medida que os animais crescem e se desenvolvem, exceto para o rendimento de carcaça até os 110 dias de idade, o que pode ser atribuído ao aumento do trato e conteúdo gastrintestinal.

Ocorrem redução no percentual de dianteiro e acréscimo no percentual de traseiro do nascimento até os 110 dias de idade, em bezerros machos não castrados, da raça Holandês e desaleitados precocemente.

À medida que o animal cresce verifica-se uma redução na proporção de osso e um incremento na proporção de gordura na carcaça.

\section{Literatura Citada}

ARAÚJO, G.G.L.; COELHO DA SILVA, J.F.; VALADARES FILHO, S.C. et al. Desempenho e características da carcaça de bezerros alimentados com diferentes níveis de volumoso. In: REUNIÃO ANUAL DA SOCIEDADE BRASILEIRA DE ZOOTECNIA, 35., 1998, Botucatu. Anais ... Botucatu: Sociedade Brasileira de Zootecnia, 1998. p.329-3331.

BANYS, V.L. Medidas barimétricas de bezerros provenientes do aleitamento com sucedâneos baseados em proteína texturizada de soja e diferentes fontes de lactose. In: In: REUNIÃO ANUAL DA SOCIEDADE BRASILEIRA DE ZOOTECNIA, 36., 1999, Porto Alegre. Anais... Porto Alegre: Sociedade Brasileira de Zootecnia, 1999. p.239.

BERG, R.T.; BUTTERFIELD, R.M. New concepts of cattle growth. New York: Sydney University, 1976. 240p.

CAMPOS, O.F.; LIZIEIRE, R.S.; ALVES, P.A.P.M. Produção de vitelos. Juiz de Fora: Embrapa - CNPGL, 1997. 22p. (Circular Técnica, 42) 
CARVALHO, S. Desempenho, composição corporal e exigências nutricionais de cordeiros machos inteiros, machos castrados e fêmeas alimentados em confinamento. Santa Maria: Universidade Federal de Santa Maria, 1998. 102p. Dissertação (Mestrado em Zootecnia) - Universidade Federal de Santa Maria, 1998.

DEL DUCA, L.O.A.; MORAES, C.O.C.; SALOMONI, E. et al. Efeito do peso de abate nas características quantitativas da carcaça de novilhos Ibagé. In: REUNIÃO ANUAL DA SOCIEDADE BRASILEIRA DE ZOOTECNIA, 36., 1999, Porto Alegre. Anais ... Porto Alegre, 1999. p.357.

DI MARCO, O.N. Crescimiento y respuesta animal. Balcarce: Associación Argentina de Producción Animal, 1994. 129p.

EUCLIDES FILHO, K.; EUCLIDES, V.P.B.; FIGUEIREDO, G. R. et al. Avaliação de animais Nelore e de seus mestiços com Charolês, Fleckivieh e Chianina, em três dietas. 2. Características de carcaça. Revista Brasileira de Zootecnia, v.26, n.1, p.73-79, 1997.

FOX, D.G.; BLACK, J.R. System for predicting body composition and performance of crowing cattle. Journal of Animal Science, v.58, n.3, p.725-739, 1984.

HANKINS, O.G.; HOWE, P.E. Estimation of the composition of beef carcasses and cuts. Washington, USDA, p. 1-20, 1946. (Technical bulletin-USDA, 1946).

KEPLIN, L.A.S. Desempenho e características das carcaças de novilhos terminados em confinamento e abatidos com pesos diferentes. Santa Maria: Universidade Federal de Santa Maria, 1989. 86p. Dissertação (Mestrado em Zootecnia) - Universidade Federal de Santa Maria, 1989.

LAUZER, J. J. Fatores indicativos do rendimento da porção comestível na carcaça de bovinos. Santa Maria, 1977. 155p. Dissertação (Mestrado em Zootecnia) - Universidade Federal de Santa Maria, 1977.

MÜLLER, L. Normas para avaliação de carcaças e concurso de carcaças de novilhos. Santa Maria: Universidade Federal de Santa Maria, 1987. 31p.

MÜLLER, L.; ALMEIDA, E.X.; MARASCHIN, G.E. et al. Qualidade da carcaça de novilhos Charolês x Nelore submetidos à diferentes pressões de pastejo em capim elefante anão cv. Mott. In: REUNIÃO ANUAL DA SOCIEDADE BRASILEIRA DE ZOOTECNIA, 34., 1997, Juiz de Fora. Anais... Juiz de Fora, 1997. p.361-363.

PEROBELLI, Z.V. Estudo das carcaças e da carne de vacas de descarte das raças Charolês e Nelore. Santa Maria: Universidade Federal de Santa Maria, 1993. 70p. Dissertação (Mestrado em Zootecnia) - Universidade Federal de Santa Maria, 1993.
PERON, A.J.; FORTES, C.A.A.; LANA, R.P. et al. Medidas quantitativas e proporções de músculo, tecido adiposo e ossos da carcaça de novilhos de cinco grupos genéticos, submetidos à alimentação restrita e "ad libitum”. Revista da Sociedade Brasileira de Zootecnia, v.24, n.1, p.126-137, 1995.

ROCHA, E.O.; FONTES, C.A.A.; PAULINO, M.F. et al. Ganho de peso, eficiência alimentar e características da carcaça de novilhos de origem leiteira. Revista Brasileira de Zootecnia, v.28, n.1, p.148-158, 1999.

STATISTICAL ANALYSIS SYSTEM - SAS. User's guide: Stactistcs. Version 6.11. Cary: 1996.

SIGNORETTI, R.D.; CASTRO, A.C.G.; COELHO DA SILVA, J.F. et al. Utilização do farelo de gérmen de milho no concentrado inicial de bezerros de raças leiteiras em sistemas de desaleitamento precoce. Revista da Sociedade Brasileira de Zootecnia, v.24, n.5, p.841-851, 1995.

SIGNORETTI, R.D.; SILVA, J.F.C.; VALADARES FILHO, S.C. et al. Crescimento, conversão alimentar e rendimento de carcaça de bezerros da raça holandesa alimentados com dietas contendo diferentes níveis de volumoso. Revista Brasileira de Zootecnia, v.28, n.1, p.185-194, 1999.

SILVA, N.L.Q.; RESTLE, J.; ALVES FILHO, D.C. et al. Aspectos quantitativos da carcaça de novilhos alimentados com silagens de sorgo associadas a três níveis de concentrado. In: REUNIÃO ANUAL DA SOCIEDADE BRASILEIRA DE ZOOTECNIA, 1999, Porto Alegre. Anais ... Porto Alegre: Sociedade Brasileira de Zootecnia, 1999. p.356.

TEIXEIRA, J.C. Exigências de energia e proteína, composição e área corporal e principais cortes da carcaça em seis grupos genéticos de bovídeos. Viçosa, MG: Universidade Federal Viçosa, 1984. 94p. Tese (Doutorado em Zootecnia) Universidade Federal Viçosa, 1984.

VELLOSO, L.; SILVA, L.R.M.; BOIN, C. et al. Desenvolvimento de bovinos mestiços holandeses inteiros e castrados, em regime de confinamento e as características das carcaças. Boletim da Indústria Animal, v.32, n.1, p.37-45, 1975.

Recebido em: 13/09/02 Aceito em: 13/12/02 